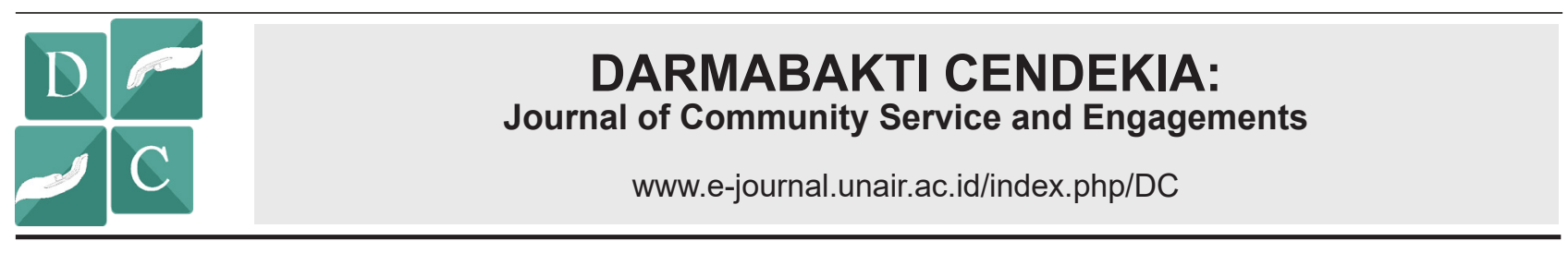

\section{IMPLEMENTATION OF ICT BASED PEDIATRIC TELEHEALTH CARE POSYANDU AS AUTOMATIC MONITOR AND IDENTIFICATION OF INFANT'S GROWTH AND DEVELOPMENT}

\author{
IMPLEMENTASI PEDIATRIC TELEHEALTH CARE POSYANDU \\ BERBASIS ICT UNTUK MONITORING DAN IDENTIFIKASI \\ OTOMATIS TUMBUH KEMBANG BALITA
}

Scope:

Applied Scicence

Riries Rulaningtyas*, Abidah Alfi Maritsa, Weni Endahing Warni, Soegianto Soelistiono, Khusnul Ain, Amirul Amalia, Aji Sapta Pramulen, Yusrinourdi Muhammad Zuchruf, Hanif Assyarify, Miranda Syafira Widyananda, Muhammad Fadhel Maulana

Study Program of Biomedical Engineering, Department of Physics, Faculty of Science and Technology, Universitas Airlangga University, Surabaya-Indonesia

\begin{abstract}
A B S T R A C T
Background: Posyandu is one of the Indonesian government's attempt in order to monitor and improve the health and life quality of the community, especially infant. However, the implementation of Posyandu is facing some issues such as low effectiveness and low accuracy during the data collecting process of the infant's growth and development. Purpose: This study aims to develop an automatic telehealth care product in order to help to increase the effectivity and accuracy in the implementation of Posyandu. Methods: (1) Development of the Telehealth Care Posyandu Application, (2) Implementation of the application in the form of social service program. Result: (1) "Toddler" Telehealth Care Application based in Android and ICT was buith with artificial intelligence of Decision Tree and Random Forest method. Program testing was done with $97.89 \%$ accuration score from total 85 infant's growth data. While from 47 questionnaire data of infant's development, accuracy score of $83.33 \%$ was obtained. (2) Target's respond on the Telehealth Care Posyandu Application shown the status of "Very Satistified" based on the score of $81 \%$ from the satisfaction survey. The satisfaction survey covered three aspects which are: System, User, and Interaction. Conclusion: "Toddler" Telehealth Care Posyandu Application was proven to has high accuracy, sensitivity, and sensitivity score and also resulted in "Very Satisfied" user respond.
\end{abstract}

\section{A B S T R A K}

Latar belakang: Posyandu merupakan salah satu upaya pemerintah dalam memantau dan meningkatkan kesehatan serta kesejahteraan masyarakat, khususnya balita. Pada pelaksanaannya, seringkali dijumpai beberapa kendala diantaranya rendahnya akurasi dan efektivitas dalam pengumpulan data tumbuh kembang di Posyandu. Tujuan: Penelitian ini bertujuan untuk membangun sebuah produk telehealth care otomatis yang dapat membantu meningkatkan efektivitas dan akurasi dalam pelaksanaan Posyandu untuk membantu dan meningkatkan kelancaran kegiatan pemantauan tumbuh kembang balita. Metode: (1) Penyusunan Aplikasi Telehealth Care Posyandu, (2) Implementasi program dalam rangkaian kegiatan pengabdian masyarakat. Hasil: (1) Aplikasi Telehealth Care "Toddler" berbasis Android dan ICT yang disusun menggunakan kecerdasan buatan Decision Tree dan Random Forest. Hasil uji program memberikan hasil akurasi sebesar $97,89 \%$ dari total 85 data pertumbuhan balita. Sementara dari 47 data kuisioner perkembangan balita didapatkan hasil akurasi sebesar 83,33\%, (2) Respon target terhadap Aplikasi Telehealth Care Posyandu menunjukkan hasil "Sangat Puas" yang ditunjukkan oleh nilai $81 \%$ dari kuisioner kepuasan yang dibagikan. Hal ini menunjukkan kepuasan pengguna dalam tiga aspek yang diujikan yakni Aspek Sistem, Aspek Pengguna, dan Aspek Interaksi. Kesimpulan: Aplikasi Telehealth Care "Toddler" teruji memiliki nilai akurasi, spesifisitas, dan sensitivitas tinggi serta user memberikan respon "Sangat Puas" terhadap kegiatan yang dilakukan.

Darmabakti Cendekia: Journal of Community Service and Engagements p-ISSN: 2657-201X; e-ISSN: 2657-1099 DOI: 10.20473/dc.v2i1.2020.39-46

Open access under Creative Commons Attribution-Non Comercial-Share A like 4.0 International License

(CC-BY-NC-SA) (c)

\author{
ARTICLE INFO \\ Recieved 21 November 2019 \\ Accepted 30 Mei 2020 \\ Online 28 Juni 2020 \\ *Correspondence (Korespondensi): \\ Riries Rulaningtyas \\ E-mail: \\ riries-r@fst.unair.ac.id
}

Keywords:

Posyandu; Telehealth Care; Artificial Intelligence

Kata kunci:

Posyandu; Telehealth Care; Kecerdasan Buatan 


\section{PENDAHULUAN}

Posyandu balita merupakan salah satu upaya pembinaan kesehatan untuk anak usia o (nol) sampai 72 bulan (Kemenkes RI, 2016). Kegiatan ini berperan penting dalam pencegahan kelainan pertumbuhan anak diantaranya adalah obesitas (Kemenkes R1, 2012), kekurangan gizi, maupun tinggi badan anak di bawah rata - rata (stunting). Selain kelainan pertumbuhan seperti yang sudah disebutkan di atas, kelainan perkembangan merupakan salah satu fokus utama dari program pemerintah serta dalam pelaksanaan Posyandu balita seperti contohnya adalah autisme dan Gangguan Pemusatan Perhatian dan Hiperaktivitas (GPPH) (Runjati, 2010).

Pada pelaksanaannya, seluruh proses pada Posyandu umumnya dilakukan secara manual, baik dari pendaftaran, pengumpulan data, serta pengolahan data. Pengumpulan data secara manual menghadapi masalah dan berbagai tantangan, diantaranya: pengambilan data membutuhkan waktu yang lama, buku yang rusak, hilang, maupun berganti, serta tulisan tangan yang sulit dibaca menyebabkan kesalahan dalam pembacaan data. Selain itu pengolahan data manual melalui grafik dan tabel memiliki risiko ketidakakuratan yang tinggi hal ini umumnya disebabkan oleh kesalahan dalam pembacaan data maupun kesalahan dalam perhitungan (Supriyanto, 2017).

Penelitian mengenai diagnosa autisme dan down syndrome telah dilakukan Mahmoudi et al., (2018) menggunakan metode Random Forest (RF) dan Support Vector Machines (SVM) dengan akurasi masing - masing sebesar 93\% dan 92\% pada aplikasi berbasis web. Pada penelitian ini juga disebutkan bahwa metode yang sama dapat dikembangkan dalam penelitian kasus ADHD.

Berdasarkan permasalahan serta tinjauan pustaka di atas dibuatlah suatu aplikasi deteksi dini kelainan pertumbuhan dan perkembangan balita yang dikemas dalam bentuk aplikasi telehealth care posyandu berbasis ICT dan Android sebagai alternatif solusi.

Setelah dipaparkan di atas mengenai latar belakang dan pendahuluan dari studi ini, selanjutnya akan dijelaskan mengenai metode yang digunakan dalam penelitian ini. Penjelasan metode penelitian sendiri akan dibagi menjadi Penyusunan Aplikasi dan Implementasi Aplikasi Telehealth Care di Posyandu Sumber Rejo. Kemudian dilanjutkan dengan pemaparan Hasil dan Pembahasan yang ditinjau dari dua aspek yakni Hasil Penyusunan Aplikasi Telehealth Care Posyandu "Toddler" serta Hasil Implementasi Aplikasi dalam Kegiatan Pengabdian Masyarakat.

\section{METODE}

\section{Waktu dan Tempat}

Keseluruhan rangkaian penelitian ini dilaksakan 15 Oktober 2018 - 5 Oktober 2019. Sementara kegiatan inti Pengabdian Masyarakat dilaksanakan sebanyak tiga kali yakni pada tanggal 7 Agustus 2019, 14 September 2019, dan 5 Oktober 2019. Kegiatan Pengabdian Masyarakat seluruhnya dilaksanakan di Posyandu Desa Sumber Rejo, Kecamatan Pakal, Surabaya dengan jumlah keseluruhan peserta sebanyak 52 orang. Dalam penelitian ini digunakan alat dan bahan berupa laptop, software Android Studio, software Weka, kabel USB, program Microsoft Excel, data pertumbuhan balita, serta data hasil kuisioner perkembangan.

\section{Penyusunan Aplikasi}

Studi ini merupakan studi implementasi suatu produk teknologi, dalam hal ini adalah Aplikasi Telehealth Care untuk Posyandu berbasis ICT, oleh sebab itu penyusunan atau pembuatan aplikasi tersebut memegang peranan sangat penting dalam keberhasilan studi. Gambar 1 menjelaskan mengenai alur proses penyusunan aplikasi yang dimulai dari proses konsultasi dengan pakar dan diakhiri dengan proses pengujian keluaran dari aplikasi.

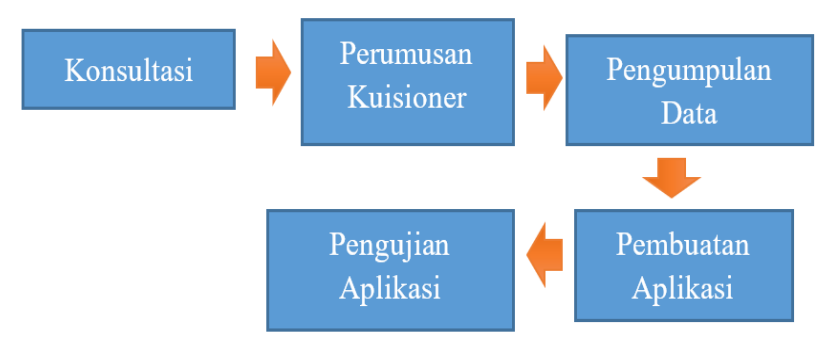

Gambar 1. Diagram alur proses pembuatan aplikasi

1. Konsultasi dengan Pakar Perkembangan Balita.

Konsultasi dengan pakar perkembangan balita, dalam kasus ini adalah dengan psikolog, diperlukan sebagai salah satu sumber basis pengetahuan dalam perancangan aplikasi. Aplikasi yang dibuat dalam penelitian ini merupakan aplikasi kecerdasan buatan (Artificial Intelligence) berbasis sistem pakar (Expert System). Pada intinya, aplikasi ini bertujuan untuk mengadaptasi kecerdasan dari ahli di bidangnya untuk melakukan deteksi/keputusan mengenai indikasi hiperaktivitas balita.

2. Perumusan Kuisioner Perkembangan Balita Dari hasil konsultasi serta diskusi dengan pakar maka disusunlah Kuisioner Perkembangan Balita yang bertujuan untuk mengetahui indikasi hiperaktivitas balita. 
Kuisioner yang digunakan memiliki 12 item yang mana kuisioner ini berdasarkan dari Diagnostic and Manual of Mental Disorder edisi kelima (American Psychiatric Association, 2016), Vanderbilt Assessment Scales (NICHQ, 2002), serta Pedoman Pelaksanaan Stimulasi, Deteksi, dan Intervensi Dini Tumbuh Kembang Anak (Kemenkes, 2016). Angka 0-3 digunakan untuk mengisi item dalam kusioner ini yang mana angka tersebut mengindikasikan seringnya perilaku teramati pada balita. Secara berurutan angka - angka tersebut mengindikasikan Tidak Pernah, Jarang, Kadang, dan Sering. Kuisioner ini diisi oleh ibu balita berdasarkan pengamatan terhadap perilaku balitanya.

3. Pengumpulan Data

Terdapat dua jenis data yang digunakan dalam penelitian ini, yakni data kuantitatif dan data kualitatif. Data kuantitatif sendiri berupa data pertumbuhan balita dan berwujud angka nilai Berat Badan (BB), Tinggi Badan (TB), dan Lingkar Kepala (LK) (Kemenkes, 2012). Sementara data kualitatif berupa hasil pengisian dari kuisioner perkembangan balita yang telah disebutkan sebelumnya. Selanjutnya kedua jenis data ini masing masing dibagi menjadi $70 \%$ data latih dan 30\% data uji.

4. Pembuatan Aplikasi Telehealth Care Posyandu Data yang telah didapatkan kemudian digunakan sebagai dasar penyusunan sistem kecerdasan buatan. Data kuantitatif digunakan untuk melakukan deteksi kelainan pertumbuhan yakni kelainan tinggi badan, kelainan berat badan, dan kelainan lingkar kepala (WHO, 2008). Untuk mendapatkan keputusan tersebut, penelitian ini menggunakan metode Decision Tree untuk mengolah data kuantitatif. Sehingga didapatkan pohon keputusan yang tepat untuk menentukan status pertumbuhan balita (Breiman, 2001).

Sementara data kuantitatif yang didapat kemudian diolah dengan metode Random Forest (Liaw, 2001). Random Forest yang digunakan dalam penelitian ini disusun menggunakan bantuan aplikasi Weka sehingga didapatkan algoritma dari 100 buah pohon acak yang tepat untuk melakukan deteksi kecenderungan hiperaktivitas.

Decision Tree dan Random Forest yang didapat kemudian diubah dalam bahasa pemrograman Java dalam aplikasi Android Studio sehingga didapatkan program deteksi kelainan pertumbuhan dan pekembangan balita dengan tampilan aplikasi Android yang menarik dan interaktif. Output dari aplikasi ini adalah berupa deteksi kelainan pertumbuhan: kelainan tinggi badan (Sangat Pendek, Pendek, Normal, Tinggi), kelainan berat badan (Sangat Kurus, Kurus, Normal, Gemuk, Sangat Gemuk), dan kelainan lingkar kepala (Microcephaly, Normal, Macrocephaly) serta kelainan perkembangan: kecenderungan hiperaktivitas rendah, sedang, dan tinggi.

5. Pengujian Aplikasi

Sebelum dilakukan implementasi, aplikasi yang telah dibuat diuji terlebih dahulu menggunakan blackbox testing, white box testing, serta confussion matrix table untuk uji akurasi, spesifisitas, dan sensitivitas menggunakan data uji yang telah disiapkan sebelumnya.

\section{Implementasi Aplikasi Telehealth Care di Posyan- du Sumber Rejo}

Implementasi dari Aplikasi Telehealth Care Posyandu "Toddler" dilakukan sebagai salah satu upaya untuk berkontribusi dalam peningkatan kesehatan masyarakat. Implementasi teknologi dilakukan dalam serangkaian kegiatan pengabdian masyarakat yang terdiri dari lima kali kunjungan resmi, tiga kali pelatihan, dua kali feedback, satu kali penyuluhan, serta satu kali pre-test dan posttest. Rangkaian kegiatan yang berkesinambungan ini dilakukan dengan tujuan untuk memperdalam implementasi dan sosialisasi dari aplikasi terdadap masyarakat. Adanya feedback dalam kegiatan ini memungkinkan masyarakat/target untuk memberikan kritik dan masukan terdahap aplikasi yang dibuat, sehingga hasil akhir dari produk teknogi yang dihasilkan akan tepat guna. Alur pelaksanaan kegiatan implementasi nampak pada Gambar 2 berikut:

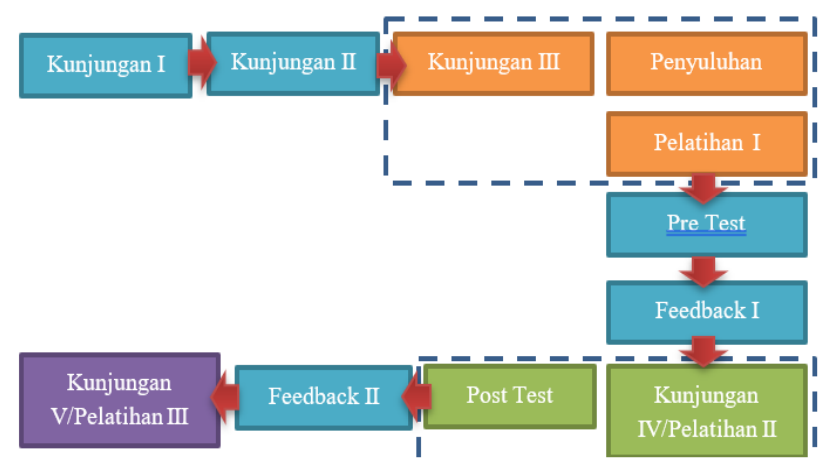

Gambar 2. Diagram alur kegiatan implementasi teknologi

1. Kunjungan I

Kunjungan I ke posyandu target yakni Posyandu Desa Sumber Rejo, Pakal, Surabaya dilakukan di awal penelitian. Kunjungan ini berfungsi sebagai sosialisasi awal kegiatan penelitian sekaligus pengabdian masyarakat. Pada kunjungan ini juga dilakukan proses 
pengambilan data baik data kuantitatif maupun data kualitatif.

2. Kunjungan II

Kunjungan II ke posyandu target merupakan proses integrasi lanjutan antara tim pelaksana disemininasi teknologi dengan perwakilan posyandu target. Kunjungan ini bertujuan untuk mempersiapkan dan menyosialisasikan kegiatan penyuluhan yang akan dilakukan pada kunjungan selanjutnya.

3. Kunjungan III

Kunjungan III dilakukan sebagai acara inti dari kegiatan pengabdian masyarakat. Pada kunjungan ini dilakukan serangkaian acara yakni pre-test, penyuluhan, serta pelatihan I.

Pre-test I bertujuan untuk mengetahui pemahaman awal masyarakat terhadap teknologi yang akan diimplementasikan. Pada pretest ini juga dilakukan screening terhadap pandangan masyarakat target terhadap kegiatan yang telah dilakukan serta harapan mengenai rangkaian kegiatan yang akan dilaksanakan selanjutnya.

Pada kunjungan III ini dilakukan penyuluhan yang terdiri dari dua buah materi dan disampaikan oleh dua orang pakar kesehatan. Materi pertama adalah penyuluhan mengenai kanker serviks yang mana materi ini sangat bermanfaat untuk peserta yang terdiri dari ibu dan balita. Adanya materi ini bertujuan untuk meningkatkan kesaradaran mengenai kanker serviks serta untuk memberikan pengetahuan mengenai cara pencegahan, deteksi, dan juga pengobatan kanker serviks. Materi kedua merupakan materi yang berkaitan erat dengan implementasi teknologi yang akan diberikan, yakni materi mengenai pertumbuhan dan perkembangan balita. Pada sesi tanya jawab, ibu - ibu balita mengungkapkan berbagai permasalahan yang muncul dalam deteksi dan monitoring tumbuh kembang anak selama ini. Permasalahan - permasalahan inilah yang nantinya akan dipecahkan oleh aplikasi telehealth care yang dibuat.

4. Pelatihan I

Pelatihan I diikuti oleh 15 kader Posyandu Desa Sumber Rejo, Surabaya. Pelatihan I bertujuan untuk menunjukkan tampilan prototype awal dari aplikasi telehealth care yang telah dibuat serta untuk memberikan sosialisasi awal terhadap fungsi dari aplikasi. Dari pelatihan pertama yang dilakukan, kader memberikan respon positif serta memberikan beberapa feedback berupa kritik, saran, dan masukan mengenai penyelenggaraan rangkaian program pengabdian masyarakat serta pengembangan aplikasi telehealth care.
5. Feedback I

Tindakan tindak lanjut atas feedback dari pelatihan I dari aplikasi telehealth care posyandu "Toddler" dilaksanakan selama kurang lebih satu bulan. Dalam proses ini dilakukan penyempurnaan tampilan sehingga aplikasi lebih menarik serta mudah dioperasikan, pengintegrasian tampilan dengan database untuk memudahkan fitur log in dan perekaman status balita, serta perancangan program selanjutnya.

6. Pelatihan II

Pelatihan kedua dilakukan kembali terhadap kader. Pada pelatihan ini, aplikasi yang sudah siap untuk digunakan dan disebarkan sehingga pada kegiatan ini para kader dilatih untuk mengunduh dan memasang aplikasi Toddler. Selanjutnya kader dikenalkan dan menguji coba secara langsung dengan fitur fitur dalam aplikasi Toddler.

7. Post-test

Post-test yang dilakukan berisi penilaian kepuasan pengguna terhadap software aplikasi Toddler yang telah dibuat.

8. Feedback II

Tindak lanjut dari pelatihan kedua adalah penyempurnaan database posyandu yang berisi data - data anggota Posyandu Sumber Rejo. Pada proses ini dilakukan input data serta pembuatan akun untuk masing - masing ibu dan balita. Data yang dimasukkan mencakup alamat email ibu, nama ibu, nik ibu, nama balita, jenis kelamin balita, dan nik balita. Tindakan ini dilakukan agar masing - masing ibu balita memiliki akun yang siap digunakan untuk menginput data serta memantau status pertumbuhan dan perkembangan masing masing balita.

9. Pelatihan III

Pelatihan ketiga dilakukan kembali terhadap kader. Pada pelatihan ini, kader diuji terlebih dahulu cara menggunakan aplikasi Toddler bedasarkan pelatihan sebelumnya. Setelah diuji, kader kembali dilatihulang menggunakan aplikasi Toddler mulai dari mendaftar akun, $\log$ in akun, deteksi dini tumbuh dan kembang anak, membuat info agenda menggunakan data asli balita Posyandu Anggrek. Selanjutnya kader dikenalkan dengan untuk melihat database balita yang telah diinputkan pada aplikasi Toddler.

\section{HASIL DAN PEMBAHASAN}

\section{Penyusunan Aplikasi Telehealth Care Posyandu "Toddler"}

Proses penyusunan aplikasi telehealth 
care posyandu menghasilkan sebuah aplikasi android posyandu interaktif "Toddler". Gambar 3 menunjukkan tampilan pertama yang akan muncul ketika user membuka program "Toddler". Tampilan ini disebut Splash Screen yang berfungsi sebagai tampilan selamat datang kepada user sekaligus mengenalkan nama dan logo dari program.

\section{Toddler}

Gambar 3. Splash screen aplikasi Toddler

Selanjutnya, apabila user pertama kali membuka program setelah melakukan proses penginstalan maka aplikasi akan menampilkan welcoming screens yang berisi tampilan mengenai fungsi singkat dari aplikasi "Toddler” yang tampak pada Gambar 4.

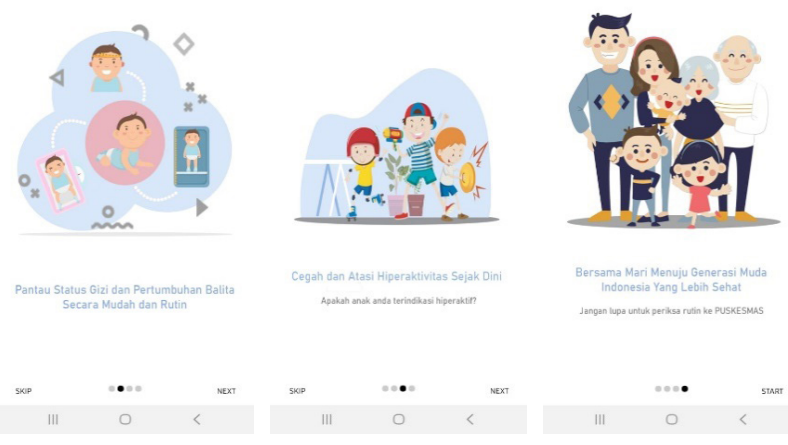

Gambar 4. Welcoming screen aplikasi Toddler

Selanjutnya aplikasi akan menampilkan log in menu agar user yang sudah terdaftar dapat masuk ke dalam akunnya. Menu log in ini membutuhkan email dan password agar dapat masuk ke dalam akun. Untuk user yang belum terdaftar dapat memilih menu "Daftar" dan mendaftar dengan memasukkan informasi ke dalam tampilan seperti nampak pada Gambar 5. Data yang dimasukkan oleh user kemudian terekam ke dalam database sistem.

Program yang dibuat juga menyediakan fitur informasi mengenai balita yang mencakup nama ibu, nama anak, nomor nik anak, tanggal lahir anak, serta jenis kelamin. Selain itu juga aplikasi "Toddler" dapat menampilkan fitur informasi
Agenda Terdekat. Fitur ini berfungsi agar admin Posyandu dapat mengimputkan agenda acara posyandu ke dalam database, kemudian notifikasi tersebut akan muncul secara otomatis pada aplikasi masing - masing user seperti nampak pada Gambar 6.
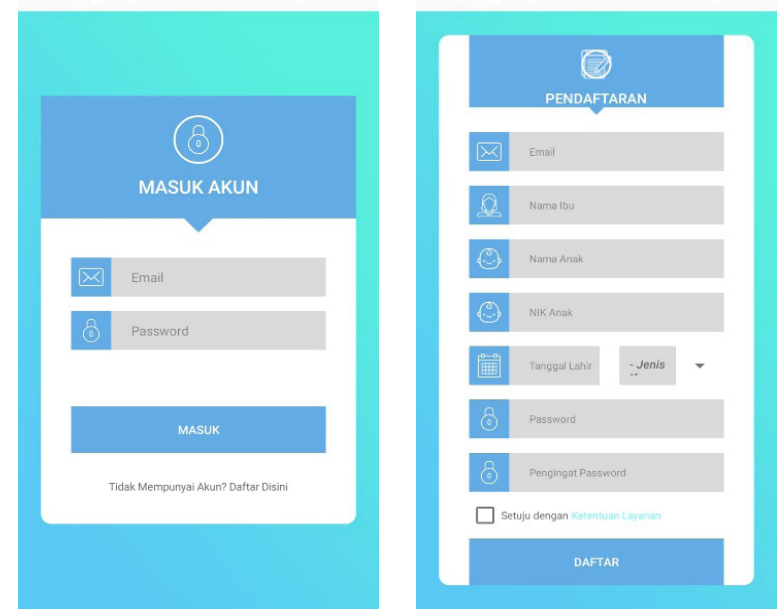

Gambar 5. Tampilan log in window (kiri) dan menu pendaftaran (kanan)
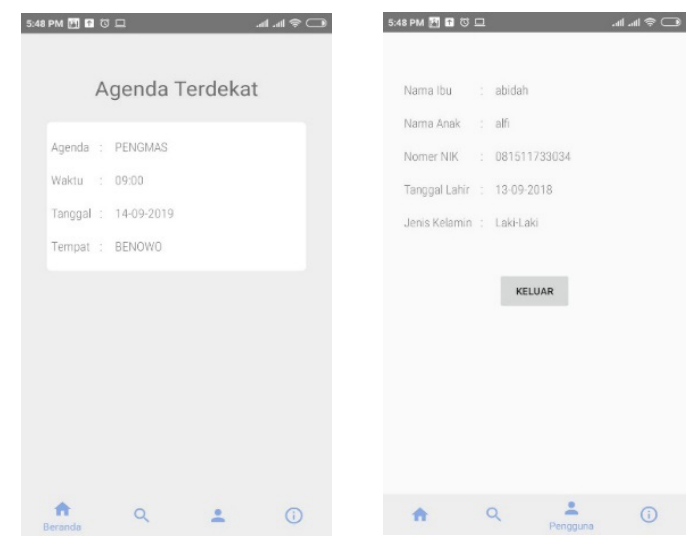

Gambar 6. Tampilan informasi balita (kiri) dan informasi agenda terdekat (kanan)

Salah satu fitur utama dari aplikasi adalah untuk memantau dan mendeteksi kelainan pertumbuhan balita seperti nampak pada Gambar 7. Pada fitur ini user menginputkan jenis kelamin balita, usia dalam bulan, berat badan dalam kilogram, tinggi badan dalam $\mathrm{cm}$, dan lingkar kepala dalam $\mathrm{cm}$ sehingga ketika user menekan tombol deteksi maka aplikasi akan menampilkan status berat badan, tinggi badan, dan lingkar kepala balita.

Fiturselanjutnyaadalahdeteksiperkembangan balita. Untuk melakukan deteksi, user diharapkan untuk mengisi kuisioner deteksi hiperaktivitas seperti tampak pada Gambar 8. Kuisioner tersebut berisi 12 pertanyaan mengenai perilaku balita 
dengan nilai 0-3. Selanjutnya apabila tombol deteksi ditekan maka aplikasi akan menampilkan deteksi kecenderungan hiperaktivitas balita dari indikasi rendah, sedang, dan tinggi.

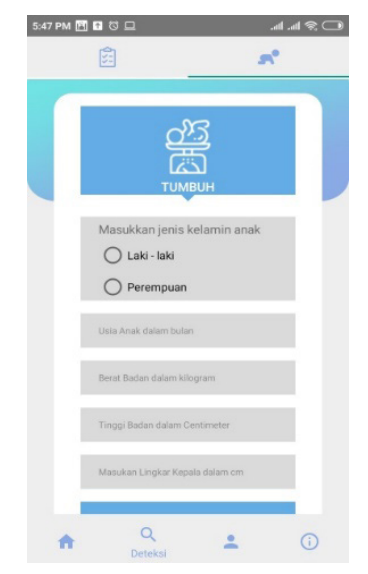

Gambar 7. Fitur deteksi pertumbuhan balita

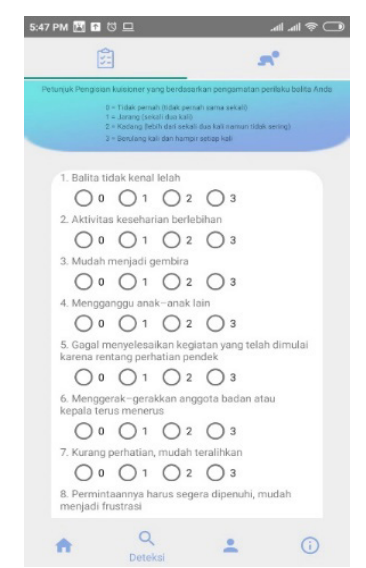

Gambar 8. Fitur deteksi perkembangan balita

\section{White Box Testing}

White box testing merupakan jenis pengujian untuk menganalisis ada tidaknya kesalahan dalam modul dan kode program yang telah dibuat. Tahapan dari white box testing yang dilakukan adalah diantaranya meneliti ada tidaknya eror pada pemrograman, mencocokkan kode dengan aturan dan logika yang telah dibuat sebelumnya, serta meneliti kode untuk tampilan program. Hasil dari white box testing sendiri menunjukkan tidak adanya eror pada pemrograman, sehingga program dapat berjalan dengan baik.

\section{Black Box Testing}

Black box testing merupakan jenis pengujian untuk meneliti apakah tampilan program sudah sesuai dengan keinginan. Uji ini dilakukan dengan cara menjalankan/mengeksekusi aplikasi yang telah dibuat. Hasil dari black box testing menunjukkan bahwa aplikasi sudah berjalan sesuai fungsi dari masing - masing bagiannya dan sudah sesuai dengan tampilan yang diharapkan.

\section{Hasil Uji Akurasi, Spesifisitas, Sensitivitas}

Uji terakhir yang dilakukan merupakan uji akurasi, sensitifitas, dan spesifitas yang bertujuan untuk mengetahui performa dari deteksi tumbuh kembang yang dilakukan oleh aplikasi "Toddler". Hasil dari uji ini didapatkan dengan cara membandingkan data latih dan data uji dengan diagnosa dari pakar.

Uji akurasi, spesifitas, dan sensitifitas yang dilakukan terbagi menjadi dua yakni uji untuk data pertumbuhan, dan uji untuk data perkembangan balita. Confusion Matrix table untuk data pertumbuhan nampak pada Tabel 1, 2, dan 3.

Tabel 1. Confusion Matrix Table untuk Kelainan Berat Badan

\begin{tabular}{|c|c|c|c|c|c|c|c|}
\hline & \multicolumn{5}{|c|}{ Predicted } & \multirow[b]{2}{*}{ Total } \\
\hline & & $\begin{array}{c}\text { Sangat } \\
\text { Kurus }\end{array}$ & Kurus & Normal & Gemuk & $\begin{array}{l}\text { Sangat } \\
\text { Gemuk }\end{array}$ & \\
\hline \multirow{5}{*}{ D } & $\begin{array}{l}\text { Sangat } \\
\text { Kurus }\end{array}$ & 1 & 0 & 0 & 0 & 0 & 1 \\
\hline & Kurus & 0 & 0 & 0 & 0 & 0 & 0 \\
\hline & Normal & 0 & 2 & 17 & 0 & 0 & 19 \\
\hline & Gemuk & 0 & 0 & 0 & 1 & 0 & 1 \\
\hline & $\begin{array}{l}\text { Sangat } \\
\text { Gemuk }\end{array}$ & 0 & 0 & 0 & 0 & 0 & 0 \\
\hline To & tal & 1 & 2 & 17 & 1 & 0 & \\
\hline
\end{tabular}

Tabel 2. Confusion Matrix Table untuk Kelainan Tinggi Badan

\begin{tabular}{|c|c|c|c|c|c|c|}
\hline & \multicolumn{4}{|c|}{ Predicted } & \multirow[t]{2}{*}{ Total } \\
\hline & & $\begin{array}{l}\text { Sangat } \\
\text { Pendek }\end{array}$ & Pendek & Normal & Tinggi & \\
\hline \multirow{4}{*}{\begin{tabular}{l}
$\bar{\sigma}$ \\
\multirow{2}{*}{} \\
$\frac{\alpha}{\alpha}$
\end{tabular}} & $\begin{array}{l}\text { Sangat } \\
\text { Pendek }\end{array}$ & 2 & 0 & 0 & 0 & 2 \\
\hline & Pendek & 0 & 4 & 0 & 0 & 4 \\
\hline & Normal & 0 & 0 & 15 & 0 & 15 \\
\hline & Tinggi & 0 & 0 & 0 & 0 & 0 \\
\hline \multicolumn{2}{|c|}{ Total } & 2 & 4 & 15 & 0 & \\
\hline
\end{tabular}

Tabel 3. Confusion Matrix Table untuk Kelainan Lingkar Kepala

\begin{tabular}{|c|c|c|c|c|c|}
\hline & \multicolumn{3}{|c|}{ Prediction } & \multirow{2}{*}{$\begin{array}{l}\text { To- } \\
\text { tal }\end{array}$} \\
\hline & & $\begin{array}{l}\text { Micro- } \\
\text { cephaly }\end{array}$ & Normal & $\begin{array}{l}\text { Macro- } \\
\text { cephaly }\end{array}$ & \\
\hline \multirow{4}{*}{ 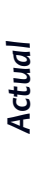 } & Microcephaly & 0 & 0 & 0 & 0 \\
\hline & Normal & 0 & 21 & 0 & 21 \\
\hline & Macrocephaly & 0 & 0 & 0 & 0 \\
\hline & Tinggi & 0 & 0 & 0 & 0 \\
\hline \multicolumn{2}{|c|}{ Total } & 0 & 21 & 0 & \\
\hline
\end{tabular}

Sementara untuk kelainan perkembangan berupa kecenderungan hiperaktivitas ditunjukkan oleh Tabel 4. 
Tabel 4. Confusion Matrix Table untuk Kelainan Hiperaktivitas

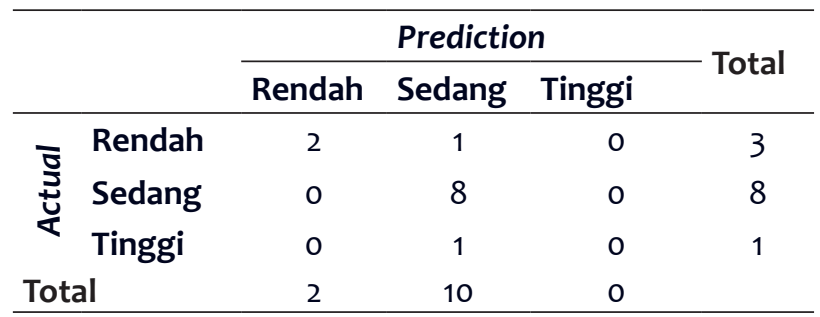

Nilai yang didapatkan dari masing - masing Confusion Matrix Table kemudian dihitung menggunakan persamaan 1, 3, dan 4 di Gambar 9. Nilai Tp adalah True positive, Tn adalah True negative, Fp adalah False positive, dan Fn adalah False negative (Gupta, 2013).

$$
\begin{gathered}
\text { Accuracy }=\frac{T_{P}+T_{N}}{P+N} \times 100 \% \\
P=T_{P}+F_{N} \text { and } N=F_{P}+T_{N} \\
\text { Sensitivity }=\frac{T_{P}}{T_{P}+F_{N}} \times 100 \% \\
\text { Specificity }=\frac{T_{N}}{F_{P}+T_{N}} \times 100 \%
\end{gathered}
$$

Gambar 9. Persamaan perhitungan akurasi, sensitivitas, dan spesifitas

Dari perhitungan yang dilakukan maka

\begin{tabular}{|c|c|c|c|c|}
\hline $\begin{array}{l}\text { Jenis } \\
\text { Deteksi }\end{array}$ & \multicolumn{2}{|c|}{ Jenis Uji } & $\%$ & Rerata \\
\hline \multirow{9}{*}{ Pertumbuhan } & \multirow[t]{3}{*}{ Akurasi } & Berat badan & 90,47 & \multirow[t]{3}{*}{96,82} \\
\hline & & $\begin{array}{l}\text { Tinggi } \\
\text { badan }\end{array}$ & 100 & \\
\hline & & $\begin{array}{l}\text { Lingkar } \\
\text { Kepala }\end{array}$ & 100 & \\
\hline & \multirow[t]{3}{*}{ Spesifisitas } & Berat badan & 98 & \multirow[t]{3}{*}{99,33} \\
\hline & & $\begin{array}{l}\text { Tinggi } \\
\text { badan }\end{array}$ & 100 & \\
\hline & & $\begin{array}{l}\text { Lingkar } \\
\text { Kepala }\end{array}$ & 100 & \\
\hline & \multirow[t]{3}{*}{ Sensitivitas } & Berat badan & 97,89 & \multirow[t]{3}{*}{99,3} \\
\hline & & $\begin{array}{l}\text { Tinggi } \\
\text { badan }\end{array}$ & 100 & \\
\hline & & $\begin{array}{l}\text { Lingkar } \\
\text { Kepala }\end{array}$ & 100 & \\
\hline \multirow[t]{3}{*}{ Perkembangan } & & Akurasi & 83,3 & \\
\hline & & Spesifisitas & 100 & \\
\hline & & Sensitivitas & 83,3 & \\
\hline
\end{tabular}
didapatkan nilai seperti yang ditunjukkan pada Tabel 5 .

Tabel 5. Hasil Uji Akurasi, Spesifisitas, dan Sensitivitas

Dari hasil di atas diketahui bahwa akurasi total program adalah $96,82 \%+83,3 \%=90 \%$, spesifitas program adalah $99,33 \%+100 \%=99,6 \%$, dan sensitivitas program adalah $99,3 \%+83,3 \%=91,2 \%$

Evaluasi hasil implementasi aplikasi dalam kegiatan pengabdian masyarakat dilakukan dengan pemberian pre test dan post test. Hasil pre-test menunjukkan bahwa 52 peserta kegiatan pengabdian masyarakat pada Kunjungan III memberikan tingkat kepuasan sebesar $84,74 \%$ terhadap materi serta acara yang disampaikan. Nilai ini menunjukkan tingkat kepuasan "Sangat Puas". Hasil post-test menunjukkan bahwa peserta kegiatan pengabdian masyarakat pada Pelatihan II memberikan tingkat kepuasan sebesar $81 \%$ terhadap materi serta acara yang disampaikan. Nilai ini menunjukkan tingkat kepuasan "Sangat Puas"

\section{KESIMPULAN DAN SARAN}

Aplikasi Pediatric Telehealth Care Posyandu "Toddler" yang telah disusun memberikan hasil deteksi dini kelainan pertumbuhan dan perkembangan dengan akurasi, spesifisitas, dan sensitivitas total sebesar 90\%, 99,6\%, dan $91,2 \%$. Aplikasi ini telah diterapkan dalam kegiatan pengabdian masyarakat dan pelatihan terhadap kader posyandu yang memberikan tingkat kepuasan "Sangat Puas" dari user yang ditunjukkan dengan presentase kepuasan sebesar 81\%. Kedepannya diharapkan aplikasi ini dapat disempurnakan dalam sisi tampilan dan logika pemrograman sehingga dapat mencapai nilai akurasi, spesifisitas, sensitivitas, serta kepuasan 100\%. Program ini juga memiliki potensi untuk dapat disebar luaskan sehingga dapat digunakan oleh posyandu - posyandu lain di Indonesia, untuk mencapai tujuan ini maka integrasi dengan pihak Puskesmas, Dinas Kesehatan, dan Pemerintah sangat penting.

\section{UCAPAN TERIMA KASIH}

Ucapan terimakasih penulis sampaikan kepada pihak Posyandu Sumber Rejo, masyarakat desa Sumber Rejo, pemerintah desa, dan jajaran terkait atas kerjasamanya dalam pelaksanaan kegiatan sehingga kegiatan dapat berjalan dengan lancar. Kedepannya diharapkan adanya keberlanjutan dalam kegiatan pengabdian masyarakat ini sehingga kegiatan ini dapat terus bermanfaat dalam memajukan kesehatan dan kesejahteraan masyarakat. Penulis menyatakan tidak ada konflik kepentingan dengan pihak - pihak yang terkait delam kegiatan pengabdian kepada masyarakat ini. 


\section{DAFTAR PUSTAKA}

American Psychiatric Association. 2016. Diagnostic and Statistical Manual of Mental Disorders 5th edition. Amerika Serikat: American Psychiatric Association Publishing.

Breiman, L. Random Forests. 2001. Machine Learning Vol. 45(1). Pp. 5-32.

Gupta, N. 2013. Accuracy, Sensitivity, and Specificity Measurement of Various Classification Techniques on Healthcare Data. IOSR J. Comput. Eng. Vol. 11(5). Pp. 70-73.

Kementerian Kesehatan Republik Indonesia. 2012. Pedoman Pencegahan dan Penanggulangan Kegemukan dan Obesitas pada Anak Sekolah. Jakarta: Kementerian Kesehatan RI.

Kementerian Kesehatan Republik Indonesia. 2016. Pedoman Pelaksanaan: Stimulasi, Deteksi dan Intervensi Dini Tumbuh Kembang Anak. Jakarta: Direktorat Kesehatan Keluarga.

Liaw, A., Wiener, M. 2002. Classification and Regression by RandomForest. Forest Vol. 2(3). Pp. 18-22.
Mahmoudi, M., Akbari-Zardkhaneh, S., Zadeh, A. A., Ghobari-Bonab, B., Shokoohi-Yekta, M., Moradi, H., Pouretemad, H. R. 2018. An Autism Screening Expert System: Reliability, Validity and Factorial Structure. Autism-Open Access Vol. 08(03). Pp. 1-7.

National Institute for Children's Health Quality (NICHQ). 2002. NICHQ Vanderbilt Assessment Scales: Used for Diagnosing ADHD. Amerika Serikat: American Academy of Pediatrics and National Initiative for Children's Healthcare Quality.

Runjati. 2010. Asuhan Kebidanan Komunitas. Jakarta: EGC.

Supriyanto, A., Hartono, B. 2017. Peran Teknologi Informasi bagi Kader Posyandu dalam Kegiatan Pendataan K.I.A. Bali: Seminar Nasional Vokasi dan Teknologi.

WHO. 2008. Training Course on Child Growth Assessment: Interpreting Growth Indicators. China: WHO Press. 